
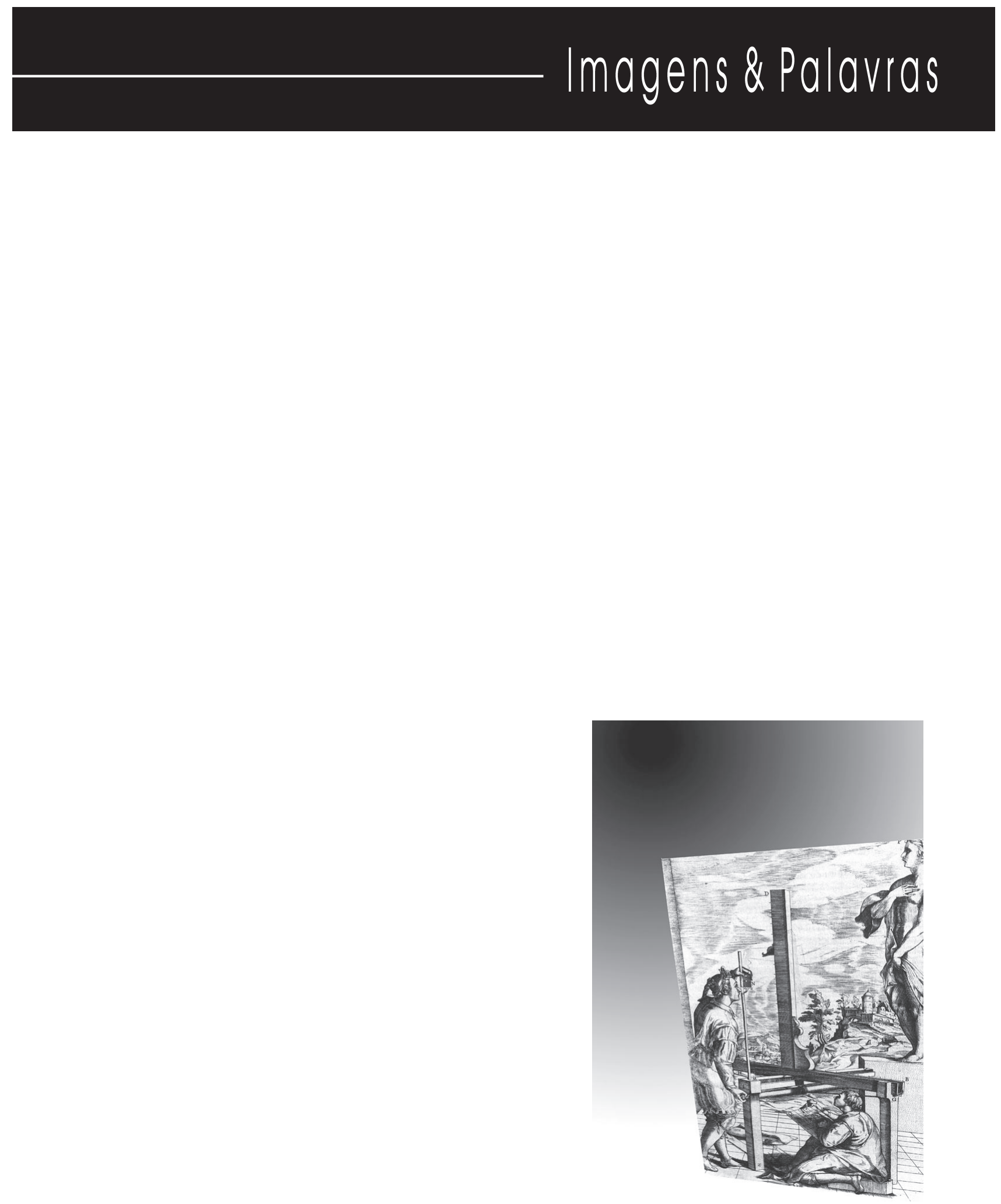


\title{
A EDUCADORA DE CRECHE: CONSTRUINDO SUAS IDENTIDADES
}

\author{
Maria Aparecida Mello
}

$E$ screver a resenha deste livro tornou-se para mim um prazer e um desafio. Um prazer porque, à medida que realizava a leitura, me reportava às situações relatadas pelas educadoras e, como não poderia deixar de ser, tecia comparações com a situação das creches brasileiras. O desafio configurou-se em produzir um resumo sobre a enormidade dos dados apresentados pelas autoras, de forma que ele pudesse revelar todo o trabalho desenvolvido por elas.

Bárbara Ongari (Departamento de Sociologia e Pesquisa Social da Universidade de Trento) e Paola Molina (Laboratório de Psicologia do Desenvolvimento da Universidade de Torino) são pesquisadoras italianas em Psicologia do Desenvolvimento e trabalham, há muitos anos, com formação de educadoras de creche e pré-escolas.

Apesar das conquistas na área de Educação Infantil, que conferiram direitos específicos à criança, tornando-a personagem central da família e da escola, tais conquistas nem sempre se traduzem em práticas educativas intencionais, coerentes com fundamentos teóricos e experiências pautadas na reflexão. As autoras argumentam que isto ocorre não apenas por razóes sociais, mas pela propagação de teorias educativas suportadas por concepçôes de desenvolvimento infantil que priorizam a dimensão biológica, definindo rigidamente a infância e a transformando em modelos dos próprios adultos. Ao contrário dessas concepções, as autoras defendem a abordagem que pressupõe uma "cultura da criança", na qual a evolução infantil não é um fenômeno exclusivamente natural e relaciona-se às circunstâncias em que a cri-

\footnotetext{
* Resenha do livro de Barbara Ongari e Paola Molina (São Paulo: Cortez, 2003. Trad. Fernanda L. Ortale e Ilse Paschoal Moreira; rev. téc. Ana Lúcia Goulart de Faria. Título Original: Il mestiere di educatrice).

** Professora adjunta do Programa de Pós-Graduação em Educação da Universidade Federal de São Carlos (UfSCAR).E-mail: mare@terra.com.br/mmello@power.ufscar.br
} 
ança está inserida. Argumentam, ainda, que as pedagogias subjacentes às idéias, expectativas e representações das pessoas que trabalham na Educação Infantil influenciam fortemente os modos de desenvolvimento das crianças pequenas. A base teórica do trabalho é pautada nas representações sociais de Moscovici (1976), centrada nas interações entre contexto e comportamento social a partir de imagens, percepções e idéias derivadas da experiência cotidiana e socialmente compartilhada.

Assim, o objetivo das autoras é compreender qual é a imagem das educadoras de creche frente à profissão e se é possível a articulação entre a indefiniçãao do modelo profissional vigente e as representaçóes que as educadoras têm sobre a sua prática.

As autoras oferecem-nos elementos para o aprofundamento da reflexão sobre o que determina a especificidade da profissão de educadora de creche e expressos nos seguintes capítulos: $\mathrm{O}$ trabalho de educadora de creche; Quem são as educadoras de creche?; A imagem do trabalho; As competências da educadora de creche; A dimensão afetiva do trabalho e A creche como serviço público.

Bárbara e Paola reconstroem alguns aspectos do histórico do trabalho das educadoras de creche na Itália, demonstrando que a partir da década de 1970 houve uma profunda mudança na história profissional dessas educadoras que passou a ter caráter cada vez mais educativo ao invés de puramente assistencial. $\mathrm{O}$ aspecto educativo desse trabalho, porém, está ainda muito indefinido, nem é válido e obrigatório em toda a Itália. Há uma variedade de diretrizes e métodos que geram modos diferenciados de conceber a relação entre adultos e crianças. Tal situação torna a educadora de creche uma profissional indefinida e anormal. Entretanto, as educadoras pouco percebem esta indefinição profissional e fazem referência, freqüentemente, ao modelo consolidado da educadora de pré-escola. Neste capítulo, a problematização e a demarcação das características desta profissão direcionam o leitor aos elementos que diferenciam a profissão de educadora de creche de outras similares, tais como: puericultoras e professoras de pré-escola.

O perfil das educadoras participantes da pesquisa é representado por uma mulher adulta, ainda jovem (30-39 anos), casada e com até dois filhos. Tem diploma de ensino médio ou de magistério, co- 
A educação de creche: construindo suas identidades

meçou a trabalhar na instituição após a passagem das creches para a gestão das prefeituras (mudança do caráter assistencial para o educacional) e os dados demonstram certa estabilidade no emprego (40\% delas trabalham na creche há mais de 10 anos). Com relação à formação continuada, as educadoras valorizam os conhecimentos intrínsecos ao "fazer" (atividades didáticas) e à aquisição de saberes referentes ao desenvolvimento infantil. Destacam o relacionamento entre as colegas como aproximadamente metade (45\%) de todas as dificuldades enfrentadas no dia-a-dia de trabalho. Este dado também foi encontrado por Angélica Maria Durens Cordeiro ${ }^{1}$ em sua pesquisa realizada no Brasil, sobre os dilemas das profissionais de creche.

Com referência à imagem que as educadoras têm do trabalho que desenvolvem na creche, os aspectos mais apontados como satisfatórios relacionam-se ao "cuidar das crianças pequenas e à estabilidade de emprego". A questão relacionada à formação é um dado interessante, uma vez que as educadoras que têm formação específica para a faixa etária de 0 a 3 anos e que afirmam ter escolhido esta profissão sentem-se mais satisfeitas que as colegas que têm formação para ensinar crianças maiores. Os aspectos relacionais e emocionais, base do trabalho com crianças, constituem ao mesmo tempo o lado gratificante e o lado opressor do trabalho. O salário inadequado é um dos aspectos insatisfatórios que é potencializado ao ser comparado com o das colegas de pré-escola. Este dado é similar à situação brasileira, que atualmente enfrenta dificuldades relacionadas à formulação de políticas públicas para uma Educação Infantil de qualidade que exige transformaçôes fundamentais e complexas relativas à formação das educadoras, como professoras, e à isonomia salarial. Os aspectos menos satisfatórios são os relativos aos recursos disponíveis na creche e o relacionamento com a administração. O cansaço e a insatisfação são diferenciados pelas educadoras; aquilo que é cansativo pode ser fonte de satisfação, enquanto que os obstáculos - insatisfação - nem sempre são considerados cansativos.

A competência das educadoras de creche está relacionada ao percurso de aprendizagem próprio. A imagem que têm da própria

*** Aluna do PPGE da UFSCAR que está desenvolvendo sua pesquisa na creche da universidade em que trabalha. A pesquisa está em sua fase final de análise e intitula-se: "Dilemas das educadoras de creche com relação ao cuidar e educar". 
profissão é específica, não relacionada a modelos que as identifiquem com dotes "naturais", "femininos", ou não-profissionais. Os conteúdos profissionais mais relevantes são os do tipo pedagógico relacionados ao que se faz com as crianças. $\mathrm{O}$ trabalho coletivo é um contexto importante de aprendizagem tanto para as educadoras quanto para as crianças. As experiências adquiridas dentro da creche (prática profissional) são mais relevantes do que a formação inicial. As autoras avaliam que esta imagem sobre a própria competência, apesar de ser positiva, pode gerar posturas rígidas em relação às solicitações advindas de fora da creche, e levantam o seguinte questionamento: “(...) é possível que uma profissão tão complexa e delicada possa ser aprendida quase exclusivamente com base na observação daquilo que as outras educadoras fazem na creche em que trabalham? Talvez a formação de base seja um problema (...)".

No capítulo sobre "a dimensão afetiva do trabalho", as autoras explicam que os dados foram coletados, principalmente, por meio de instrumentos quantitativos e padronizados e, por isso, oferecem apenas alguns pontos para reflexão, apontando o caráter afetivo do trabalho como um vasto campo de pesquisa a ser investigado. Nesta dimensão existe a dupla presença - educadora e mãe -, entretanto, não é um modelo preponderante entre as educadoras. Ter filhos ajuda apenas em certos aspectos práticos, como a identificação de doenças contagiosas. Para a maioria das educadoras/mães, o trabalho na creche tem reflexo positivo no relacionamento com os filhos, mas não fornece segurança absoluta, pois costumam ficar ansiosas do mesmo jeito, apesar da experiência profissional. A maioria concorda, parcialmente, que os mesmos métodos utilizados no trabalho aplicam-se aos filhos e, ainda, compartilha da idéia de que o componente afetivo seja um elemento central na atuação prática, desde que seja equilibrado em relação a todas as crianças sob o seu cuidado.

No tópico sobre a creche como serviço público, os dados revelam que, na imagem das educadoras, são menos importantes o apoio da administração e o relacionamento com as famílias para o bom funcionamento e boa qualidade do serviço da creche. $\mathrm{O}$ aspecto pessoal e a harmonia do grupo de trabalho são considerados, unanimemente, elementos fundamentais neste propósito. A relação entre as profissionais da creche e a administração municipal é freqüentemente difícil. 
A educação de creche: construindo suas identidades

As educadoras referem-se à falta de apoio na organização do serviço, o não reconhecimento do trabalho, relações excessivamente burocráticas, negligência em relação às exigências das crianças e das famílias e, ainda, o fato de sempre terem tido como secretários municipais de Educação pessoas que não têm relação com o trabalho desenvolvido por elas nas creches. Apesar da relação com a administração não gerar satisfação, também não cria problemas, uma vez que este componente não faz parte daqueles que produzem estresse e cansaço, e sim o fato de precisar trabalhar com crianças muito pequenas e com seus pais (dimensões internas do trabalho).

As autoras finalizam com reflexões acerca da exígua exploração, como campo de pesquisa, do trabalho de educadora de creche na Itália. Argumentam que esta profissão assumiu notável importância social nos últimos quinze anos devido a três razôes: o aumento dos conhecimentos sobre o desenvolvimento da criança nos primeiros anos de vida; a atenção diferenciada que a sociedade dedica à qualidade das experiências precoces na formação da personalidade da criança e as mudanças político-culturais que propalam a credibilidade social da creche.

Este livro traz importante contribuição para discussões e reflexôes acerca do trabalho das educadoras de creche. A qualidade da pesquisa realizada pelas autoras revela-se na abrangência da coleta dos dados nas principais regiōes da Itália e na análise cuidadosa e fidedigna dos resultados. É leitura essencial para alunos e docentes que pesquisam sobre a Educação Infantil; para pessoas que exercem cargos de gestão em creches e para aqueles que formulam políticas públicas para a educação de crianças pequenas. Não posso deixar de aludir às açôes de formação continuada e em serviço de educadoras de creche, presentes na realidade brasileira; as autoras fornecem análises importantes que podem ser incorporadas nas reflexóes dos docentes que realizam tais ações. 